\title{
Communication and Digital Emotions: The Desire of Community as a Dimension of the Existence
}

\author{
Simona Perfetti \\ Rosario Ponziano
}

\section{Abstract}

According to Ong (1986), for a long time, in the human history, direct or vis$\grave{a}$-vis communication has been the only modality of communication; traditions have essentially been oral and their survival depended on the continuous renewal, which was represented by the vis-à-vis narration of stories and activities. In this way, the oral culture has created some expedients to remind and let people remind some aspects: a certain structure of the speech (fixed themes, formulas, proverbs, rhythmic style, etc.), a particular kind of (narrative) speech, a specific behavioral schematization ("strong" characters, types). The communication process is always a fundamental and essential process (Wright, 1976): it involves individuals in a deep relationship inside which the linguistic and paralinguistic codes, which come into play, take on complex meanings. In fact, despite the apparent facility through which two or more people come into contact among them, the deep sense of communication is something which is complicated and mysterious. Each person, who is involved in the communication process, attributes, on the basis of his/her subjective and social-group existential experience, his/her own meaning to each sign. According to Wolton (2006), communication has to do with four dimensions, which are complementary among them: first of all, communication is the ideal of expression and exchange which is at the origin of the Western culture and of democracy; talking about democracy presumes, as a basic concept, the existence of free and equal individuals. Communication concerns also those media which have remarkably transformed the relationships between communication and society. Still, communication concerns the whole mechanism of the new technologies that, with information science, telecommunications, audiovisuals and their interconnection, have globally modified the premises of the exchange of messages and power. In the end, communication includes also all those values, those symbols and those representations which function as a mechanism for the functioning of the public space, of democracies and of the international community through information and media. ${ }^{12}$

\footnotetext{
${ }^{1}$ Rosario Ponziano has written the paragraphs: 1. Communication, yesterday and today and 2. Loneliness and freedom of the person between mediated communication and digital emotions. The educational gamble.

${ }^{2}$ Simona Perfetti has written the paragraphs: 3 . The origins of communication. Dialogue and narration and 4 . The desire of community and digital emotions. Educational reflections.
} 
Keywords: communication, digital, emotions, desire, community, dimension, existence

\section{Introduction}

\section{Communication, yesterday and today}

Today the advent and consolidation of digital media have expanded and, partly, modified the ways and contents of communication. In such perspective, the introduction of new media has an impact both on the evolution of the communication process and on the social context in which the media appear. Digital media create new kinds of action and interaction and new forms of social relationships, thus determining a complex restructuring of the dimensions of space, time and memory. All this leads the contemporary individual to feel alone in his/her choices of the behaviors because nobody is able to give certainties any longer, with the exception of the temporary and revocable certainties (La Marca A. 2016; Prensky, 2001).

The educational occasions offered by the new technologies of the communication:

Suggest the urgency of a new network of relationships with the traditional educational practices, with the school culture and its curricular structure. Knowledge tends to become more and more performative, cross, shared, cooperated. The urgency of a new tribal feeling takes shape, of a community dimension in which intelligence may find a point of interaction, even if it is projected in more and more virtual spaces of understanding, of work production (Salzano, 2000, p. 7).

By making a step backward in time it is useful to recall the thought of some Authors, who reflected on the changes of the communication in relation to the advent of media and the Internet. In that sense, Thompson (1998) distinguished two typologies of mediated interaction in contraposition with the vis-à-vis interaction: a "mediated interaction" which develops with the aid of a technical means among individuals, who are far in space and/or time, and that circumscribes the series of symbolic addresses, which are available to the participants; an "almost mediated interaction" which allows, instead, to exchange symbolic contents among individuals, who are far in space and/or time, according to a flow of unidirectional communication, which addresses to a potentially undefined group of people. Many of the relationships, which are established in daily life in this way, consist of a combination of different forms of interaction: in other words, they are hybrid. If, according to Thompson, the current forms of communication may be defined as "hybrid", in Wolton's point of view, cinema, radio and television on the one hand, and the advent of the Internet on the other, led the current society to be defined as a mass egotistical society (Wolton, 1997). According to Wolton, television and the Internet meet two different needs, the person and the mass' needs: freedom for the person, equality for the mass. The generalist television creates some communication relationships, which are more and more developed for more and more heterogeneous groups of audience. Since, today, 
we live in a more and more complex and problematic society in which different cultures coexist, television and radio may represent a sort of "bridge" among desires, preferences and fears of the different social groups since, with their systems of symbols, which are broadly shared, and a wide choice of programs which, just for this diversity, meet everybody's tastes, they allow to rediscover the fundamental elements of staying together.

On the contrary, the advent of the Internet represented, for the person, an educational dimension to be lived "in loneliness", because the person chooses by himself/herself the communication paths in order to implement his/her own cognitive map.

Therefore, Wolton's thought aims at not opposing old media to the new media, since what is important in communication is both the content and the role that the different media have inside a communication theory; we must not confuse technical progress and human and deep sense of communication; it is not technology which makes communication, but people and the society (Wolton, 2001).

Nowadays, the real challenge of communication, on the basis of the changes in the communication during the time, concerns the elaboration of a theory of communication which may be able to guarantee the individual communication through the Internet on the one hand, and the mass communication on the other, which may play the role of guaranteeing the social unity.

\section{Loneliness and freedom of the person between mediated communication and digital emotions: The educational gamble}

The crisis of deep relationships and identities which seems to characterize the current connected society (Ito, 2008) leads the person to live the relationship with the others in a manner which might be defined of "circular solipsism" (Wolton, 2001), a relationship which significantly reveals itself in that nomadic wandering which characterizes the social dimension of the Internet. To complicate the context, there is the fact that the person's identity is a reality, which is not isolated but that changes following the spirit of the time. In order to understand that, it is necessary to start from what Boccia Artieri (2012) defined as a mediological approach, that is, thinking about the media as a place for the construction of paths of sense, both individual and collective paths, as elements which influence the social reality.

In a time in which digitization and dematerialization are leading the person towards the categorical imperative of a widespread showcase (Ferrarresi, 2009), the identity necessarily appears weak and fragmented. In that sense the Internet represents the instrument which allows to "play" with identities, without having the restriction to remain tied to one of them. Therefore, the media represent some experiential sources in order to live a sort of "virtual extraterritoriality" in the ambit of which, as Bauman (2003) affirms, the identity represents a task which is not performed yet: 
Identity as something which is necessary to build or select among alternative options: "who am I?". The sense of this question finds its basis only if the individual knows he/she can be someone different from what he/she is, if he/she must do something in order to reinforce and make a choice "real" (p. 29).

In the area of this new anthropological dimension, which is made of identity crisis and of a new emotional régime, the barriers between the public and private spheres fall, or rather public and private spheres become two dimensions which risk blending. In such perspective the neologism publicy (Boyd, 2007) indicates this mixture between public sphere and private sphere which, by generating a new culture of intimacy, fixes new educational challenges. In such perspective, in a society in which communication and information are omnipresent, an educational challenge, which is in line with the times, might become real not so much by bringing together individuals or collectivities, but by managing and acknowledging the mutual differences. Dealing with a constructive and pedagogical subject on the awareness and management of the differences as an anthropological value broadens the reflection up to the ambit of online life: how are the identity and awareness of the others lived on the Internet? In the ambit of the social media different lives and identities are experienced. People:

by dissimulating and fragmenting their own identity, lead, however, in the new environment, their own history, which, in intervals, erupts with strength (Massaro Grotti, 2000, p. 41).

In the protected space of the Internet the deepest thoughts are shared, the most determined opinions are affirmed, and it is possible to reach a multitude of people in a fast and instantaneous way:

Above all it is possible to keep one's own identity concealed: everybody may choose the person that he/she wants to be, everybody may behave as he/she better likes (Cantelmi, Grifo 2002, p. 53).

In the era of digital communication, of a fast communication, which is without rules, the "I" necessarily moves in a dimension which is different if compared to that in which his/her body moves, since the actions of the "I" consist of language, symbols and writing. In this complex anthropological perspective, the "I" and the other person seem to exchange the communication roles in a continuous game of "ephemeral" cross references just because they are disengaged from the corporeity. This absence of bodies and traces and this sort of identity vacuum which already characterize the whole social totality, even if they seem to be some dimensions which, in a certain sense, facilitate the virtual meeting with the others, actually they lead the educational reflection towards the acknowledgement that the contemporary person is always more alone in a myriad of "alterities"; such condition of isolation is rather more difficult to be lived just because the current age is an age which is marked by a form of communication, which is faster and faster and more and more instantaneous (Vittadini, 2018; John, N.A. 2013). 
Even if the technical and scientific developments have caused a severe reduction in the distances among individuals, the crux to be solved is the existential discomfort of the modern individual, a discomfort which is marked by a loneliness, that is much more desperate when it is linked to a form of "apparent" freedom. In other terms, the person, nowadays, is as if he/she lived in a sort of dilemma: on the one hand, tending towards the others may be seen as a tension aiming at promoting the differences, to the other hand the individual, "by living" an immaterial age, would seem that he/she runs the risk of losing sight of the deep sense of what is humanly possible. Even if in the virtual world of the Internet it is possible to play with the absence of the bodies and with the simultaneity and increase of the communication paths in order to apparently facilitate the need for talking about himself/herself and talking to himself/herself, the emotional aspects, which lead to search for online relationships, are more complex. In order to realize the multiplicity of the elements into play, it is necessary to reflect on the fact that, thanks to the mediation of an instrument, the person succeeds in telling and telling about himself/herself more and more easily, if compared to a vis-à-vis meeting.

In the ambit of the online communication game, since the essential aspects of the not verbal communication start lacking, some compensatory criteria of the missing piece of information follow; in the world of digital media, it is possible to experience images, words, and sounds as forms through which it is possible to express the modern creativity.

The ways of communicating have surely changed, and even if a cognitive order is given to online life, anyway, basically there is the need for being listened to and understood in a dimension which includes and embraces us. The Internet offers the great possibility to take advantage of a new way in order to communicate our emotions, for telling about them in freedom, but a freedom which must not be misunderstood and interpreted as an absence of rules; it is rather a search for new rules, which are different from those which were known and used in the past.

Today the person already lives a world of messages which are not identifiable any longer with the only verbal messages or with messages which come from other people; in the current society of the crisis, it is the whole environment which "speaks" (Pati, 2000). In such "entirely communicative" environment, also the ultimate sense of the word seems to have been overcome by the power of images; even when it seems that the word succeeds in prevailing still on all the other linguistic codes, always a "particular word" remains, a word which, as the person, feels strongly the effect of the environmental influence; hence, the more growing number of "set phrases", through which the individual expresses his/her feelings, even if most of times he/she does it by using lines of films or advertising slogans; words, as emotions, seem already to have become "consumer goods" (Pati, 2000).

Therefore, if the word and emotions risk this "commercialization", how is it possible to try to make an educational path which takes into consideration the development of 
all the existential dimensions? Emotions as feelings, which are lived online, are emotional dimensions as the real ones; it is not by simplifying the issue and by affirming that "real emotions are more authentic than the online ones" that those, who deal with education, solve the person's educational problems. On the contrary, education has to lead the reflection not to exclusively privilege the oral language and writing as unique means in order to communicate but, by distancing itself from a glottocentric vision of communication, it has to embrace a rich and broad series of expressions of the body and technological instruments which the individual, in the course of the history, has always produced in order to tell about himself/herself and to tell stories, projects and utopias. The language of the body is a language to which human and social sciences have to pay full attention in the prospect of a multiplicity of factors, which may manage and integrate the original expressions of the thought with the contemporaneous ones of digital media.

Faced with such dimensions of crisis, which have invaded the whole person's existence, the educational proposal consists of elaborating a philosophy of the existence which exalts life, which gives strength to everything that may be useful to promote the human existence. This anthropological need of a "rediscovery" of the person in the world becomes more and more an educational need; it is not sufficient to hope in the conception of new relational systems, what is necessary to modify is the overall concept of life which is a delicate path towards the acquisition of the form, towards the capacity of building an existential project. In this undertaking towards the achievement of our unique and unrepeatable form, it becomes urgent to understand the naturality of the failure, of the existential defeat, of the risk, of the unsuccessful vis-à-vis with the others. Educating to communication means to talk about a form of communication which has to recover a sense which is not connected to simple technology, but to social and cultural dimensions. In other words, the sense of a humanistic philosophy of communication has to be identified "in dreams, projects, utopias" (Buber, 1958, p. 238). The educational communication arises from willfulness, it is identified with gestures and actions led by conscience, it pursues some objectives aiming at acquiring form and, by virtue of that, it may not lead the individual to search for false forms of freedom and mystifying manifestations of being vis-à-vis with the others; on the contrary, the educational communication leads the person to reflect on the fact that his/her own's unique and unrepeatable form is not a human characteristic which is conquered once and for all in a definitive manner but it is, instead, a dimension, a peculiarity of the troubled existence, which the individual constantly and with difficulty searches for, since past life means to transcend, plan, open up with the others continuously without, in any case, having the confirmations of a return and acknowledgement.

Martin Buber wrote that freedom:

is a bridge, not an abode. Freedom is the vibrant tab, is the fruitful ground zero. Constraint in education means a lack of union, humiliation and rebellion; a deep 
relationship of reciprocity in education means open-mindedness and comprehension; freedom in education is the possibility of union and collaboration (Buber, 1958, p. 238).

Buber's words let us reflect on the importance of the concept of communication integration, which has not to be confused with the annulment of each person's singularities; in educational terms, communicative integration rather exalts the differences in the ambit of the dialogic unity and in the ambit of education to communication. Dealing with issues such as freedom, loneliness, existential defeat, the exaltation of differences leads human and social sciences to think education over, in terms also of comprehension and compassion, thus bringing into prominence of the educational issue the development of human life in all its historical, cultural and social dimensions.

\section{The origins of communication: Dialogue and narration}

Today education should reflect on a cognitive path in which thinking and acting are not distinct but, on the contrary, they converge, thus sharing the person's essential themes. That's why it is primarily important to reflect on a person and his/her life with his/her shadows, with his/her vacuums of conscience, with his/her awareness to be fragile but, just for this reason, open to the possibility, to the incentives of an educational project which has to lead him/her to succeed in the constructive relationship with the others, in a dimension of intersubjectivity which always draws new incentives from the dynamics of circularity.

Letting the others understand what one says means not only to transmit contents, but it also means to guarantee their emotional resonance. The language, at least in its declaratory form, highlights some relationships - above, under, behind, in front of, here, there, etc. - but for another intelligence which understands, relationships are never neutral, they can be meanings. And for another subject who wants, relationships and meanings mean values (Laeng, 1982, p. 104).

Alberto Granese (2008) observed how the term "to communicate" derives from the term "community", which, in its turn, is an inseparable concept from the "closeness" one. The word "communication", in fact, derives from the Latin verb communico, that is, "to put in common", which has the same etymological origin of the noun communitas, that is, "community". Still, communitas comes from the Latin expression "cummunus", that is, "cum" = with, together, "munus"= gift; communication is etymologically connected to the idea of community, that is, to the "gift of the mutual relationship".

In the ambit of the pragmatic school of human communication of Palo Alto, among the axioms of communication expressed by Watzlavick (1971), it emerges that it is impossible not to communicate; the action of communicating represents a behavior, and given that it is impossible that a living system may not have a behavior, the impossibility of the non-communication follows. 
In the reticular dimension of the Internet, an analogous space in which it is possible to experience "new" lives and "new" ways of communicating, the constant question which accompanies the person in the continuous discovery of "new" ways of approaching himself/herself and the others, is if such universe may represent the end of the communication, which is, from a teleological point of view, intended as a construction of a community, or if information highways may open infinite spaces in order to experience unusual and unexpected forms of communication.

If what is affirmed by Watzlavick is true in the "real" life, in the online life where does the fundamental sense of a communication lie, a communication which, no matter how digital, always keeps its original meaning of "putting in common"?

Reflecting on the fact that communication has, as its original function, the connection with the others means also that human communication always refers to a dialogue, that is to that dimension, which is the most adequate for the achievement of the social environment. In fact, if the explosion of new technologies has also led to radical changes in the way and form of communicating, however, the deep motivations have remained unchanged, motivations which, since the origins, have originated the dialogue and the narration (Piromallo Gambardella, 2000), which have been the first forms through which people have built their relationship with their own counterparts and the world. A careful reflection on this last aspect sheds light on the fact that the narration and the dialogue have always accompanied the individual's existence and today they still go on doing it through digital media. The surfing without space and without time on the Internet ensures that the dialogue - which moves between orality and writing - enters a global dimension. In that sense, the complexity of the dialogic dimension ensures that the dialogue may be considered the first expression of the language just because, through the language, the person, by interacting with his/her own counterparts, has always established, as his/her final objective, the will to share with the others his/her own activity and habitat:

When the homo faber starts constructing the first hand tools, he contemporaneously feels the need for 'communicating' that to the others in order to have their collaboration and for 'passing on', to the youngest people, the acquired technique in order to not lose it. It would seem that it is possible to start talking about an awareness, which is still at an early stage, about owning a 'memory'; anyway, what can be affirmed with greater certainty is that the homo loquens is more or less contemporaneous of the homo faber ${ }^{1}$. (Piromallo Gambardella, 2000, p. 42).

In this same perspective, Rossi-Landi in "Il linguaggio come lavoro e come mercato" ("The language as labour and market", Note of the Translator) lingers over the problem of the relationship between "material" and "linguistic" artifacts in order to highlight the deep homology; in that sense the two kinds of artifacts are products of the individual's work and, in both products, natural and social dimensions are present. 
Therefore, the two kinds of artifacts, which are those which distinguish us from the animal world, have appeared at the same time of the history of civilization; in fact, the person, in the course of the history, has never produced linguistic artifacts without producing, at the same time, material artifacts and viceversa:

Man could not have worked at any object if not by communicating, from a linguistic point of view, with other workers (...); and, on the contrary, the linguistic communication supposes a world of real objects which the speech refers to (Rossi Landi, 1968, p. 154).

So, the idea of an antecedence of the dialogue in the development of the communication finds a confirmation in the original need for cooperation among the individuals. In the perspective of the idea of the language, as a means in order to come into connection with the world through the relationship with the others, Vygotskij's thought is well integrated: with his reflections on the child language, he revealed how the language, in its evolutionary path, goes through a first stage, the external language, through which the child starts organizing a form of communication with the others. Whereas Rossi-Landi lingered over the dialogue as a common dimension between material employment and linguistic employment, Vygotskij lingered over the connection between thought and language through a progressive development of the same language starting from an initial dialogic dimension;

The main function of the language, both in children and adults, is the communication, the social contact. The very first child's language is, therefore, essentially social. Initially it is all-inclusive and cross-functional; subsequently, its functions become differentiated (Vygotskij, 1956, p. 37).

In the ambit of Vygotskij's thought, the other two differentiations are established by the egocentric language and by the internal language, which are two linguistic dimensions that are connected between them, also because the internal language represents a natural evolution of the egocentric language. Then, the verbal thought delineates the time in which the meanings of the words move towards more complex dimensions thanks, above all, to a structural change of the individual conscience of the person who speaks; the verbal thought tends to express:

All the thoughts, sensations and even the deepest reflections, with only the word, which is obviously untranslatable on the level of the external language and, semantically, it is not reducible to the meaning that it usually has (p. 219).

If compared to the external language, the egocentric language represents the path from interpsychic dimensions to those intrapsychic ones, that is, from a social activity to an individual one. As far as the internal language is concerned, instead, in it a restructuring of the same language materializes both at a semantic level and at a synctatic level; in other terms, the objectives that the external language pursues have to do with the establishment of communication relationships; those which are pursued by the internal language, instead, have the objective to furnish the adequate 
word to the thought, the development path of which goes from the social to the individual sphere. In Vygotskij's viewpoint, thought and language are not part of a unique dimension:

They are rather similar to two circles which intersect but which do not overlap entirely, since (...) there is a pre-linguistic phase in the use of the thought and a preintellectual phase in the use of the language. In those parts in which the two circles overlap, thought and language become "the key in order to understand the nature of the human conscience" (Piromallo Gambardella, 2000, p. 44).

Therefore, the dialogic nature is the first and important expression of the child language, which, secondly, has to be internalized if it has to become an important means for the flow of the thought. In such game of returns between thought and language, the meaning of the word becomes an expression of the thought but not through the dialogue, which is "a form of immediate and not premeditated communication"; so:

To the structural simplicity of the dialogue the complexity of the monologue opposes, which introduces the verbal facts in the sphere of the conscience and that makes them a subject of great attention (Vygotskij, 1956, p. 204).

So, what it is useful for our discussion is that, according to Vygotskij, the dialogic activity represents only a sort of the initial part of the communication game when, that is to say, the thought has not fully reached its awareness yet, which, after, is reached in the internalization of the linguistic dimension.

That's why it is possible to affirm that the dialogic activity fully pervades the experience of those subjects who are involved in the communication dimension on two levels: on the one hand speaking is an activity which has to do with the dimension of the enunciation - we talk about something to somebody -, on the other, the same enunciation is a dimension which modifies the individuals concerned, thus transforming them in "links of a chain", who find a continuous redefinition in the relationship with the others, both at a synchronic and a diachronic level.

In this perspective of "original dimensions" of the communication, after the dialogue, also the narrative occupies a space of experience of knowledge and acknowledgement of the "I" in the community. In fact, in the individual's history, narrating has been one of the first modalities through which the individual has started wondering about the sense of the world and life. Morin, in his book "Il paradigma perduto. Che cos'è la natura umana" ("The lost paradigm. What is the human nature", Note of the Translator) affirmed that the birth of the homo sapiens starts when, for the first time, man instituted the ritual of the burial with the first pictorial signs in caves; in fact, in this way, thanks to the dimension of the image and symbol, the person escaped the fear of death: 
it is in this 'anthropological rift' that the narration originates, a narration which breaks the person's primigenial unity and destines him/her forever to confront himself/herself with another dimension. Burying dead people is the final and initial act of the long story of life and death and of death which becomes again life in another form or in another place. It is the first trace of all those infinite series of tales where the words struggle for 'telling' life against death (Piromallo Gambardella, 2000, pp. $57,58)$.

Also graffiti inside caves have represented, for the person, the possibility of realizing a vision of the world, which is alternative to the real one, in order to face everyday life with greater serenity:

Each human being, without knowing it, knows that he/she is a self which may be narrated, who is absorbed in the spontaneous self-narration of his/her memory (Cavarero, 1997, p. 48).

Therefore, if the dialogue and narration may be considered the original, primogenital forms of communicating, today with the advent of digital media which seems to nourish dreams, hopes and utopias of a community, that hopes that the unlimited communication may be a synonym of deep relationships, what dimensions may these two original forms of communicating assume? If, as we have seen, dialogue has been useful for the individual in order to survive and the narration in order to live (Piromallo Gambardella, 2000), today, in a certain sense, these two dimensions continue to give rhythm to the person's life. Whereas media images, as graffiti, show the person the possibility to create a world, which is analogous to the real one in order to better face the real world, the network communication offered by the Internet is always the result of that individual's innate need to tell and tell about himself/herself; also in the media multiform environment one survives and lives; the two concepts and their respective dimensions, dialogue and narration, have only changed their "patterns".

\section{The desire of community and digital emotions: Educational reflections}

It is useful to reflect on the fact that communication has implied and, still today, continues to imply a social relationship, in the course of which people involved in the communication game share particular meanings; therefore, talking about sharing of meanings leads the reflection on the sense of communication in terms of a dimension which, from a teleological point of view, is aimed at constructing a community. According to Ferdinand Tőnnies (1963), the community is a dimension in which a group of people live together and share the same feelings, the same origin, the same fundamental teleological aspiration, that is, staying together; therefore, the community is a natural, intimate, union which is created on the basis of a mutual understanding. On the contrary, society life is public and "artificial", since it is built on interest relationships. 
This distinction between community and society has been reexamined by Nancy, according to whom it is wrong to compare the concept of community to the concept of society, since there is not any lost community to be rebuilt; society has only replaced a kind of community, the "participatory" community, that is a group of different people who, maybe, lived - even if there was a stricter and poorer social structure if compared to that one of our current society - some intense communication experience, since they had values and ideals in common; Nancy writes (1995):

The community, far from being what the society would have lost or infringed, is what happens - a matter, an event, an imperative - starting from the society (p. 37).

That's why it is not necessary to regret a lost community but, thanks to the multiform world of digital media, it is useful to try to reconstruct a new original community; there is no a "subject" who interacts with other "subjects", but there is a "singularity" which emerges inside a community. Therefore, since singularities do not presume to be eternal, they share limited dimensions of their living; it's a:

Logic of limit, a logic of what belongs neither to the pure inside, nor to the pure outside, a logic which characterizes the human being, through whom it places itself between the crowd's breakup and the group aggregation, and both are possible, virtual, close at any time. This suspension characterizes the human being with: a relationship without relationship, a simultaneous exposure to the relationship and to the essence of the relationship (pp. 182, 183).

Then, according to Nancy, community and society intertwine, since individual freedom is always:

"Freedom in common", which is fulfilled in the practice of the community life, that is in the "communication of distinct singular human beings, who exist as such only through communication" (p. 210).

A so intended idea of community may be compared to the dimension of online communities which, even if they do not have the constitutive elements of traditional communities, first among everything the rooting on the territory, preserve "the gift of the mutual relationship".

In the ambit of online life, groups of people meet in order to exchange information, establish relationships. This situation often arises on the basis of feelings of strong solidarity. In this respect, the Web is as if it were a flow in flood, which overflows with information, knowledge, emotions to be lived and shared, different points of view also with respect to the same issue. In order to avoid the risk of a cognitive overload, some time ago, Lévy (2000) had proposed the metaphor of the "small arks", that is some virtual communities in a continuous flux, which are fluid, light, that may represent, in the ambit of this information sea without boundaries, some lifelines from the "overflow" of information. 
In the ambit of these small arks in a continuous flux, individuals shall have to be committed to reconstructing some "partial totalities", according to one's own criteria of knowledge; this "fleet" of small arks represents:

A myriad of small distinguished, open, temporary totalities, which are obtained through an active filtering and which are perpetually reconsidered by collective intelligence groups which cross, are so close, collide or intertwine on the wide water of the deluge of information (Lévy, 2000, p. 157).

The newness of his thought may be deduced from the fact that the small arks, since they are living human communities, allow knowledge to circulate, even if in a context of dynamism and transience; such arks represent the place where knowledge may be continuously increased and redefined; they are not utopic, even if they are not positioned in any place and in any physical space. Therefore, if the fundamental sense of communication is making community, may online communities, which arise on the basis of an exclusive communication connection, be considered just like real communities?

In the community, the subjects do not find a principle of identification - and neither they find an aseptic fenced area within which it is possible to establish a transparent communication or, maybe, the contents to be communicated. They only find that nothingness, that distance, that unrelatedness, which makes them be missing to themselves. Community is not a way of being of the individual, but his/her exposure to what interrupts the closure and reverse him/her on the outside (Esposito, 1998, p. XVI-XVII).

Therefore, the community, as a vacuum but also as a desire; in that sense, "not belonging to" may represent the incentive to expose himself/herself to the others and so "interrupt" the closure of the "I" (Piromallo Gambardella, 2000). In other terms, this situation of not-belonging to might be seen as the representation towards externality which, today, seems the most significant dimension of the time; such path towards externalization would include also the community that:

Through the relationship to the others makes the subject "other" also vis-à-vis himself/herself, (thus letting the community become) the movement of his/her (...) flux, which is always and only "other" (Moroncini, 1991, p. 71).

Today the person finds himself/herself living a situation of deep complexity and criticality: this original ethical relationship which connects individuals, thus creating a community, transmits a power to the same community, which is less and less the product of a natural inclination and more and more the result of a mythical construction (Piromallo Gambardella, 2000). Today this sort of nostalgia of the community just identifies with a nostalgia of the myth of origin: 
Told through the word which wants to be sacred, binding, innocent and that, gradually, may be transformed in a speech which generates fear and anguish of the responsibility ${ }^{1}$. (Piromallo Gambardella, 2000, p. 159).

In the complex current society that sense of sacredness, of reunion is not assigned to the word any more, but the word finds itself living in a dimension made of games of simulation, images which have replaced its original semantic meaning; the myth is as if it had been interrupted and the idea of community which survives is the idea of a desire, of a return to an age which does not exist any longer. This state of interruption does not want to mean annulment of the community but, rather, it wants to affirm the coming out of a "passion of the community", which overcomes any limit, thus avoiding the danger to appear as a closure, as an accomplishment (Piromallo Gambardella, 2000).

In fact, even if online communities lack those characteristics of traditional communities, this state of nomadism not only represents a "laceration" towards externality, but it also avoids the obstacle which, instead, might be typical of traditional communities, that is that of transmitting a form of "closed" knowledge. If it is true that the ultimate goal of communication is that of "connecting", of facilitating the contact, then the state of "infinity" of online communities would well align with the deepest sense of the human communication, that is, that sense of never crystallizing in a hypothetical balance, because what is "finite" may not be considered life.

Talking about passion as a need for community seems to be a dimension which characterizes the community between:

The absolute rooting in an 'idealized' nature and the total exposure to the non - place of utopia. (In such perspective) it becomes a point of transit and, therefore, an ephemeral point, but, at the same time, a necessary point of transit: a space of inclusion and exclusion, abode and journey, permanence and peregrination, the ones and the others together and neither of the two (Piromallo Gambardella, 2000, p. 63).

In other terms, the so intended community appears as a mediation, which is, above all, intended as a space of sharing among opposite dimensions: individual vs. society, local $v s$. global, nostalgia vs. utopia; such opposite dimensions, just for their afore mentioned characteristics of the community, never stop in a balance, but, dialectally, they appear as a situation of a continuous renegotiation of their meanings on the basis of the necessities and needs, which continuously emerge and change in online nomadism:

Being is essentially being in common. Being in common means that singular individuals are, show up, appear only since they make their appearance, are exposed, 
introduced or offered to one another. This appearance is not added to their being, but it is what in which their being reaches the being (Nancy, 1995, p. 123).

\section{Bibliography}

[1] Bauman Z. (2003). Intervista sull'identità, Publishers Laterza: Rome-Bari.

[2] Boccia Artieri G. (2012). Stati di connessione. Pubblici, cittadini e consumatori nella (Social) Web Society. FrancoAngeli: Milan. boyd d. (2007). Why Youth (Heart) Social Web Sites:The role of Webed Publics in Teenager Social Life, in D. Buckingham (edited by),Youth, Identity and Digital Media. MIT Press: Cambridge.

[3] Buber M. (19589). Il principio dialogico. Editions of Community: Milan.

[4] Cantelmi T., Grifo L. G. (2002). La mente virtuale. L'affascinante ragnatela di Internet. San Paolo: Cinisello

[5] Cavarero A. (1997). Tu che mi guardi, tu che mi racconti. Feltrinelli: Milan.

[6] Esposito R. (1998).Communitas. Origine e destino della comunità. Einaudi: Turin.

[7] Ferraresi M. (2009). La vetrina digitale, in A. Abruzzese, M. Ferraresi (edited by) Next. Identità tra consumo e comunicazione, Lupetti: Bologna.

[8] Granese A. (2008). La conversazione educativa. Eclisse o rinnovamento della ragione pedagogica. Armando: Rome.

[9] Ito M. (2008). Introduction, In KazYs V. (ed.). Webed Publics. MIT Press: Boston.

[10] John, N.A. (2013). The Social Logics of Sharing. The Communication Review, vol. 16(3), 113-131).

[11] La Marca A. (2016), Competenza digitale e saggezza a scuola. Brescia: Publishing house: Morcelliana

[12] Laeng M. (1982). Informazione, comunicazione, educazione, in C. Stroppa (edited by), Il bambino come comunicazione. FrancoAngeli: Milan.

[13] Lévy P. (2000). Cybercultura. Gli usi sociali delle nuove tecnologie. Feltrinelli: Milan.

[14] Massaro D., Grotti A. (2000). Il filo rosso di Sofia. Etica, comunicazione e strategie conoscitive nell'epoca di Internet, Bollati Boringhieri: Turin.

[15] Moroncini B. (1991).La comunità impossibile, in B. Moroncini, F.C. Papparo, G. Borrello (edited by), L'ineguale umanità. Comunità, esperienza, differenza sessuale. Liguori: Naples.

[16] Nancy J. (1995). La comunità inoperosa. Cronopio: Naples.

[17] Ong W. G (1986). Oralità e scrittura: le tecnologie della parola. Bologna: il Mulino.

[18] Pati L. (2000). (edited by), La giovinezza. Un nuovo stadio per l'educazione. Publishing house: La Scuola: Brescia.

[19] Piromallo Gambardella A. (2000). Le sfide della comunicazione. Laterza: Rome-Bari. 
[20] Prensky, M. (2001). «Digital Natives, Digital Immigrants». On the Horizon, Vol. 9 No. 5, Cambridge: University Press.

[21] Rossi-Landi F. (1968). Il linguaggio come lavoro e come mercato. Bompiani: Milan.

[22] Salzano D., (2000) (edited by), Comunicazione ed educazione: incontro tra due culture. Naples: L'Isola dei Ragazzi.

[23] Thompson J. B. (1998). Mezzi di comunicazione e modernità: una teoria sociale dei media. Bologna: il Mulino.

[24] Tónnies, Comunità e società (1963). Editions of Community.

[25] Vittadini N. (2018). Social Media Studies. I social media alla soglia della maturità: storia, teorie e temi. FrancoAngeli: Milan.

[26] Vygotskij L. S. (1966). Pensiero e linguaggio. Giunti-Barbera: Florence.

[27] Watzlawick P., Beavin J. H., Jackson D. D. (1971). Pragmatica della comunicazione umana. Astrolabio: Rome.

[28] Wolton D. (1997). Penser la communication Flammarion: Paris.

[29] Wolton D. (2001). Internet e poi?... Teoria critica dei nuovi media. Publishing house Dedalo: Bari.

[30] Wolton D. (2006). «Intervista pubblicata» Nuova Umanità n.165/166- MayAugust 2006. 